\title{
PROCEDURAL ASPECTS OF EDUCATIONAL CHANGES: EMPIRICAL FINDINGS AT INSTITUTIONAL LEVEL
}

\author{
Inna Semenets-Orlova \\ National Academy for Public Administration under the President of Ukraine, Kyiv, Ukraine \\ innaorlova@ukr.net
}

The researcher analyses special procedural aspects and important tools of organisational change management (at the level of higher educational establishments). As part of the study, the expert survey was conducted for the purpose of collecting empirical data for the analysis of practical experience of active participants of educational changes. The author surveyed 65 specialists from Ukraine who study the educational change issues in higher educational institutions in their professional or social activities. The survey was conditionally divided into several sections: general, procedural, resources provision of change, instrumental, analysis of change results, informative and analytical, expert evaluation of governmental educational change administration in Ukraine. The majority of questions concerned the determination of the required conditions for successful implementation of educational change. Based on the analysis of contemporary scientific literature, the author defined the logics and consistency of procedures of preparation for and immediate implementation of educational change. The omission of at least one of these procedures threatens the result of the overall process of educational changes. The author suggests that the low efficiency of educational change implementation in Ukrainian educational establishments is caused by neglect or improper use of essential preparation tools and procedures of proper educational change management support (underestimation of needs for sufficient resources, advisory support, awareness-raising campaigns, administration support, stimulation of participants and necessity of their continuous training).

Keywords: educational change; procedural aspects of educational changes; policy of educational changes; educational change implementation; participants of educational change.

\section{Introduction}

A strategic necessity for the contemporary society to turn into a learning environment for everyone depends on continuous successful educational changes. Kotter (1995) argues that up to $70 \%$ of all change initiatives fail and states that the most common cited cause of the phenomenon is the educators' resistance. Burnes (2015) stated that, first of all, an organisational context should be prepared for planned transformations. Such context can be determined by interest of staff members at the lowest operational level (i.e. teachers in educational institutions) in new ideas, methods, solutions. Analysing certain situations of educational change implementation processes at organisational level by means of a questionnaire, we will make a conclusion about the level of preparedness of organisational environment of educational institutions (higher schools in particular) in Ukraine for changes. At present in the Ukrainian society there is a huge demand for changes, though a certain disbelief in successful completion of the already introduced reforms exists. The higher school reform initiated by the adoption of the Law of Ukraine "On Higher Education" (2014) still goes on and does not prove to be as successful as expected. In our opinion, the reason of low institutional competence of higher educational establishments lies in certain unpreparedness of educators of higher schools to implementation of massive administrative changes into practice of continuous professional improvement.

Issues of change management in public organisations were studied by Bourgon (2008) and Jacobsen \& Andersen (2014), who emphasised on the need of taking a fresh look at change management now as never before (Bourgon, 2008, p. 396). Understanding of efficiency of the planned educational reforms being dependent on the support of their participants at the lowest operational level is mentioned in works of Fullan (2007), Erwin \& Garman (2010) and others. Successful attempts to create models of innovations were made by Kotter (1995). Efficient tools of educational changes became the issue of research of Blaze \& Bjork (2010), McLaughlin (1998), who also analysed the issues of micro policy of educational changes. Factors of the efficiency of educational changes, particularly procedural aspects of the process of their successful implementation, were investigated by Levine \& Cooper (1991), Fullan (2007), Stanley (2006). In this article, we will analyse the mechanisms of implementation of changes in higher educational institutions of Ukraine and the causes of low efficiency of educational change implementation in them resulting from neglect of some essential preparation tools and procedures of proper educational change management support. 


\section{Method}

During February-June 2016 for the purpose of studying the causes of complications of educational change implementation, we conducted an expert survey which involved analysis of practical experience of active participants of educational changes. The survey consisted of questions which helped reveal how the national educational change practices are in line with scientifically-based recommendations regarding the process of educational changes. We surveyed 65 specialists who study the problem of educational change in their professional or social activities. The surveyed experts were the members of the following interest groups of educational reform: 34\% - assistant professors of universities and colleges, $21 \%$ - (senior) teachers of universities and colleges, 9\% - professors of universities and colleges, $15 \%$ - heads of institutions, structural subdivisions of universities, $19 \%$ - public officials in education, $2 \%$ - public figures. Among the participants, $14 \%$ of experts noted that they were active in the educational change issue research but did not take any part in processes of educational changes in practice. Other experts who were active in practical implementation of educational changes were asked 40 multiple choice questions with a chance to provide their own answer. Conditionally divided into several sections, the survey contained questions allowing an interviewee to choose several answers at once. A majority of questions concerned the conditions required for successful implementation of educational change. We asked the experts to analyse their recent experience of changes.

\section{Results}

General section. $65 \%$ of the surveyed experts participated in implementation of changes in educational process, $35 \%$ - in implementation of educational changes related to organisational development of institutions (changes in the system of continuing professional development of teachers), 19\% - in implementation of administrative educational changes. $62 \%$ of the surveyed persons participated in implementation of educational changes as participants, 39\% - as initiators, $23 \%$ - as leaders (8 experts had two roles and 6 experts had three roles at the same time). The majority of the surveyed participated in small changes involving implementation of isolated non-systemic innovations and only $11 \%$ joined implementation of massive systemic changes of a radical novel nature. Correspondingly, the audience, which the implemented changes were applied to, in $58 \%$ cases consisted of $50-200$ people, in $23 \%$ - of $500-$ 1000 people, in $14 \%$ - of $10-20$ people, in $7 \%$ - of 1 million and more. The rest $7 \%$ of the respondents also participated in changes at the level of an educational institution (that included about 1000 persons), thus, we asked them to analyse their own experience of participation in educational changes at institutional level during the survey. In terms of characteristics of educational change goal feasibility, $82 \%$ of the surveyed stated that the change included a small number of achievable goals, $14 \%$ - found a big number of hardly achievable goals, $4 \%$ - evaluated a goal /goals as mostly unachievable.

Procedural section. When asked if participants understood the content and goals of changes, $64 \%$ of experts answered, "partly", 27\% - "yes", 9\% - "difficult to answer". When asked if participants were properly consulted before the beginning of change, $55 \%$ answered - "to a certain extent", $39 \%$ - "yes", $5 \%$ "no". When asked about the provision of important conditions of the process of changes, elaboration and free access of participants to a detailed schedule (plan) of change, $61 \%$ of the experts said that they had such access, 39\% - that they did not have it, 43\% mentioned that before the beginning of the change implementation process, the participants were presented with some reasonable facts which showed how the change would lead to improvement of the system or its elements, $41 \%$ mentioned that only some of these data were provided by the initiators, $16 \%$ - that the data for verification of the reform efficiency were not provided at all. When asked about analysis of potential risks which may occur in the process of change, 38\% of the experts stated that a question of risks was not brought up at all, 52\% - that the risks were mentioned briefly but were not analysed, $18 \%$ - that the question of risks was properly analysed. Only $20 \%$ of respondents noted that the content of change was consistent with the strategy of the organisation development, $50 \%$ - answered that it was partly consistent, $30 \%$ - said that the content of the educational change was not consistent with the strategy of the organisation development.

Section of resources for change implementation. The vast majority of respondents $(60 \%)$ evaluated resources for change implementation as "insufficient", $16 \%$ stated that "change was not provided with resources at all" and $24 \%$ - mentioned a complete provision of resources for the whole process. It was revealed that $48 \%$ of respondents did not have enough equipment, $43 \%$ - "time", $39 \%$ - "funds", $36 \%$ "competent staff", $20 \%$ - "leadership potential of the administration and participants". The support of colleagues in the process of changes by the experts was evaluated by $79 \%$ of respondents as "insufficient", by $16 \%$ - as "absent", and only by $5 \%$ - as "absolute". The level of support by administration was evaluated as follows: $68 \%$ of respondents mentioned that the support was partial, $25 \%$ - full, $4 \%$ - absent at all. 
Instrumental section. Experts identified the following motives to take part in changes: care about students $(55 \%)$, care about the image of the organisation (32\%), inner need for creative work (20\%), demand for the future professional growth (13\%). 39\% of the experts stated that at the stage of change implementation open discussions were strongly encouraged, $32 \%$ said that they were "encouraged to a certain extent", $23 \%$ - that they were not encouraged at all. When asked if there were any informal groups of employees that defiantly showed resistance to change, $52 \%$ of the respondents answered "no", $14 \%$ - "yes", $45 \%$ of the surveyed stated that "most employees did not care at all". $52 \%$ of respondents who faced resistance in the process of change implementation mentioned that it appeared at the stage of actual change implementation, $20 \%$ revealed it at the stage of "formation of the concept", $14 \%$ - when discussing the implementation plan. $66 \%$ of the surveyed experts stated that in the process of change sometimes there were conflicts, $29 \%$ - that there were no conflicts, $3 \%$ - that there were regular conflicts, $2 \%$ - that there was only one conflict. $66 \%$ of the experts noted that those participants of change who showed resistance to change used methods of administrative pressure. Among the main factors hindering the introduction of change 39\% of experts mentioned "lack of resources", $30 \%$ - "disinterest of different groups of participants of change (students, staff members)", 21\% - "lack of administrative support", 11\% - "incompetence of performers".

Section of analysis of the educational change results (reflection). The results of changes implemented in practice were evaluated by $73 \%$ of the experts as partly successful, by $6 \%$ - as "unsuccessful", and only by $21 \%$ - as "completely successful and put into permanent practice". When asked about any negative effects, $45 \%$ of the experts pointed out that they did not feel any negative effects of the process of changes, $38 \%-$ said that change caused stress and exhaustion, $13 \%$ - thought that changes distracted them from the main job, $13 \%$ - that changes "came amid prolonged uncertainty, sometimes apathy", $5 \%$ - that they "made a negative impact on the professional status-quo", $4 \%$ of the experts found that the changes made a negative impact on their private lives". When the experts who were initiators / leaders of change were asked about probable further prospects of the change development, 32\% of them said that they were not sure if the change would continue in case they left the institution, $29 \%$ - expressed certainty that the change would work, $25 \%$ - that certain efficient elements of change would work, $14 \%$ - thought that the change would not work. When asked if they would take part in change implementation under the same conditions, according to the same rules and with the same resources, 52\% answered "yes", 39\% - "did not know", 9\% - "no".

\section{Discussion}

The results show low success rates of educational changes at institutional level and low level of staff preparedness to implementation of changes - only $21 \%$ of educational changes were successfully implemented.

Based on the results of our study and building on Stanley's (2006, p. 7) positions that the most important factors of success which influence the consistency of results are elaborate planning and preparations for change and comprehensive provision of communication among participants, we can assume that:

1. The extent of change support depends on the understanding of the content of the changes by participants. Thus, the latter should be consulted before the changes start. According to the results of our survey only in $27 \%$ of educational change cases participants had a clear idea of content and goals of changes, which proves inadequate awareness-raising activities. The process of changes should begin with the formulation of a strongly justified reason to change, a clear vision of "what to change" and "how to change". Otherwise there is no point in expecting participants to take potential change weaknesses in a nonjudgemental manner. An emphasis on staff capacity building through continuing training is crucially important. Our study confirmed that only in $11 \%$ cases of the educational change, participants had all the necessary skills for implementing these changes. It shows the neglect of necessity to train the participants of changes in local universities and colleges, presumably due to financial considerations.

2. The result of innovation policy depends on how the policy is interpreted and transformed at each stage of the process as well as on the responsibility of individuals at the end of the implementation process (McLaughlin, 1998, p. 72). As the practice of educational changes shows, the most common mistake of educational administrators is that they may choose a model of change without analysing whether it is useful for the educators (Fullan, 2007). Successful changes depend on team building, increase of collaboration between all participants, open leadership which encourages staff members to continuous independent development, active involvement of the administration.

3. As shown in the results of the survey, one of the major factors which hinder the implementation of changes is indifference of participants resulting from their lack of motivation. It has been empirically established that besides inner motivation, financial incentives positively correlate with innovations as they support a clear and consistent understanding of the criteria which are used to measure the high productivity 
of work. Moreover, a combination of tolerance for an early failure and a reward for a lasting success is more effective for motivation of innovativeness than a fixed salary scheme (Bysted \& Jespersen, 2013).

4. Training and group dynamics are most efficient for overcoming resistance against the planned changes. It is easier to change individuals gathered in groups than to change each one of them separately. Greater resistance of the staff requires greater engagement of workers in procedures of changes, which means that each worker has to become a subject of analysis (Burnes, 2015). Taking criticism into considering is a manifestation of wisdom. The opinions of the opposition may help to find important answers which were lost in the initial phase of the change initiative due to excessive enthusiasm of initiators. According to Zaltman and Duncan (1977), attentive strategic planning of the change may undo reasons of resistance. Also, it is crucially important to build a consensus among all the parties concerned. According to the observations of Blaze and Björk (2010, p. 241), resistance to changes at the micro political level has a tendency to strengthen during the period of externally imposed changes.

\section{Conclusions}

Low preparedness of change participants at the institutional level is caused by the low preparedness to change implementation at the national level. The autonomy of universities and colleges of Ukraine and the provision of high quality of educational services require continuous innovative activities, support of initiatives and implementation of changes at the level of organisations. According to the results of the conducted survey, at the level of educational institutions, initiators and leaders of changes neglect many necessary preparatory procedures and do not use a number of effective educational change implementation tools. Therefore, it negatively affects the readiness of the overall education system for implementation of the systemic changes in Ukrainian education. Educational change is a complex long-term process which requires special preparation and "cultivation" from the inside. For the purpose of changes in education that ensure sustainable progress in the field, it is important to maintain the following conditions at the level of different educational institutions: necessity of scientific and advisory support, gradual implementation and system monitoring of results, provision of required informational flows, formation of a proper socially adaptive background, determination of balances of powers and responsibilities of administrative and public institution authorities, avoidance of change projects lacking necessary resources.

\section{Acknowledgments}

Thanks to all the educators, active participants of educational changes who took part in the survey.

\section{References:}

Blase, J., \& Björk, L. (2010). The Micropolitics of Educational Change and Reform: Cracking Open the Black Box. In A. Hargreaves, A. Lieberman, M. Fullan, \& D. Hopkins (Eds.), Second International Handbook of Educational Change (pp. 237-58). London, New York: Springer https://doi.org/10.1007/978-90-481-2660-6_14

Bourgon, J. (2008). The Future of Public Service: A Search for a New Balance. Australian Journal of Public Administration, 67(4), 390-404. https://doi.org/10.1111/j.1467-8500.2008.00597.x

Burnes, B. (2015). Understanding Resistance to Change - Building on Coch and French. Journal of Change Management, 15(2), 92116. https://doi.org/10.1080/14697017.2014.969755

Bysted, R., \& Jespersen, K. (2013). Exploring managerial mechanisms that influence innovative work behavior: Comparing private and public employees. Public Management Review, 16(2), 217-41. https://doi.org/10.1080/14719037.2013.806576

Erwin, D. G., \& Garman, A. N. (2010). Resistance to organizational change: Linking research and practice. Leadership \& Organization Development Journal, 31(1). 39-56. https://doi.org/10.1108/01437731011010371

Fullan, M. (2007). The New Meaning of Educational Change (4th ed.). London and New York: Routledge, Taylor \& Francis Group.

Jacobsen, C. B, \& Andersen, L. B. (2014). Performance Management in the Public Sector: Does It Decrease or Increase Innovation and Performance? International Journal of Public Administration, 37(14), 1011-23. http://doi.org/10.1080/01900692.2014.928317

Kotter, J. P. (1995, March/April). Leading change: Why transformation efforts fail. Harvard Business Review, 73(2), 59-67.

Levine, D. U., \& Cooper, E. J. (1991). The Change Process and Its Implications in Teaching Thinking. In L. Idol \& B. F. Jones (Eds.), Educational Values and Cognitive Instruction: Implications for Reform (pp. 387-410). New York: Lawrence Erlbaum.

McLaughlin, M. (1998). Listening and Learning from the Field : Tales of Policy Implementation and Situated Practice. In A. Hargreaves, M., Lieberman, A., Fullan, M., \& Hopkins, D. (Eds.), International handbook of educational change (Vol. 1, pp. 70-84). London: Kluwer academic. https://doi.org/10.1007/978-94-011-4944-0_4

Stanley, G. (2006). Seven Principles for Change Management. Retrieved May 18, 2016, from Faculty of Education and Social Work University of Sydney website, http://sydney.edu.au/education_social_work/professional_learning/resources/papers/Stanley G_06_SustainableLeadership.pdf.

Zaltman, G., \& Duncan, R. (1977). Strategies for planned change. New York: Wiley. 